Supplement of Clim. Past, 16, 699-712, 2020

https://doi.org/10.5194/cp-16-699-2020-supplement

(c) Author(s) 2020. This work is distributed under

the Creative Commons Attribution 4.0 License.

(c) (1)

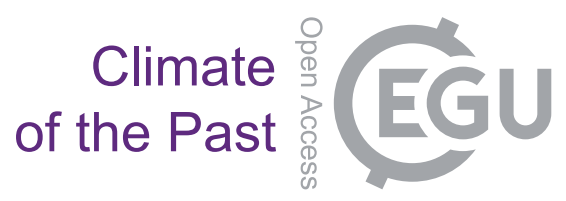

Supplement of

\title{
A new multivariable benchmark for Last Glacial Maximum climate simulations
}

Sean F. Cleator et al.

Correspondence to: Sean Cleator (s.cleator@surrey.ac.uk)

The copyright of individual parts of the supplement might differ from the CC BY 4.0 License. 
1 A new multi-variable benchmark for Last Glacial Maximum simulations: Supplementary

4 Sean F. Cleator ${ }^{1}$, Sandy P. Harrison ${ }^{2}$, Nancy K. Nichols ${ }^{3}$, I. Colin Prentice ${ }^{4}$ and Ian Roulstone ${ }^{1}$

6 1: Department of Mathematics, University of Surrey, Guildford GU2 7XH, UK

7 2: School of Archaeology, Geography and Environmental Science, University of Reading, 8 Whiteknights, Reading, RG6 6AH, UK

9 3: Department of Mathematics \& Statistics, University of Reading, Whiteknights, Reading RG6 6AX, UK

4: AXA Chair of Biosphere and Climate Impacts, Department of Life Sciences, Imperial College London, Silwood Park Campus, Buckhurst Road, Ascot SL5 7PY, UK

This supplementary information contains maps of the multi-model mean climate (SI Figure 1) and its standard deviation (SI Figure 2) of the ensemble of simulations of the Last Glacial Maximum from the Palaeoclimate Modelling Intercomparison Project (PMIP), as well as maps of the original site based reconstructions from Bartlein et al. (2011) and Prentice et al. (2017).

SI Figure 1: The multi-model mean climate of the ensemble of models from the Palaeoclimate Modelling Intercomparison Project (PMIP). The individual plots show the simulated (a) moisture index (MI), (b) mean annual precipitation (MAP), (c) mean annual temperature (MAT), (d) mean temperature of the coldest month (MTCO), (e) mean temperature of the warmest month (MTWA) and growing degree days above a baseline of 5॰ C (GDD5).
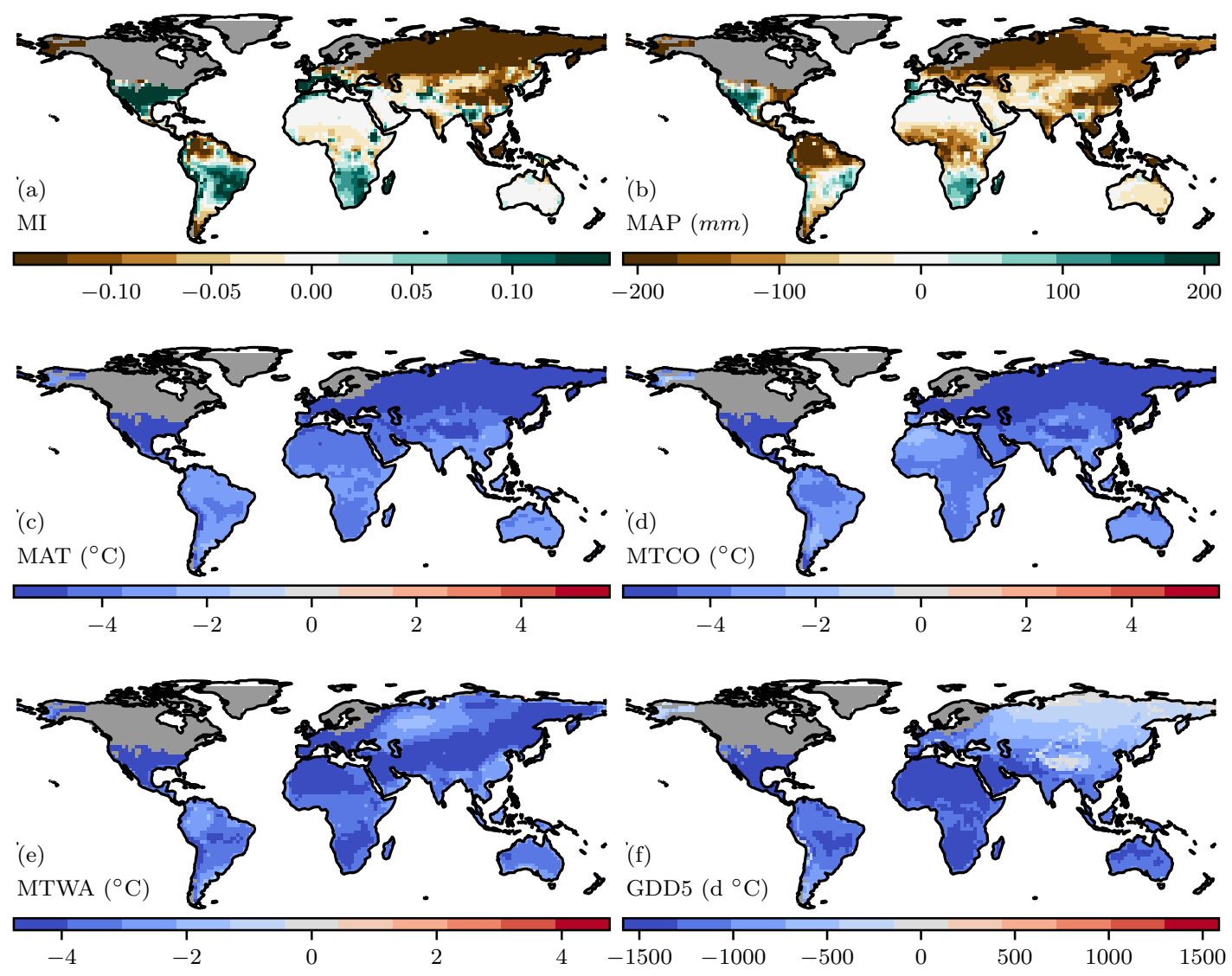
26 SI Figure 2: The standard deviation of the multi-model mean climate of the ensemble of models from

27 the Palaeoclimate Modelling Intercomparison Project (PMIP). The individual plots show the 28 simulated (a) moisture index (MI), (b) mean annual precipitation (MAP), (c) mean annual 29 temperature (MAT), (d) mean temperature of the coldest month (MTCO), (e) mean temperature of 30 the warmest month (MTWA) and growing degree days above a baseline of 5॰ C (GDD5).

31
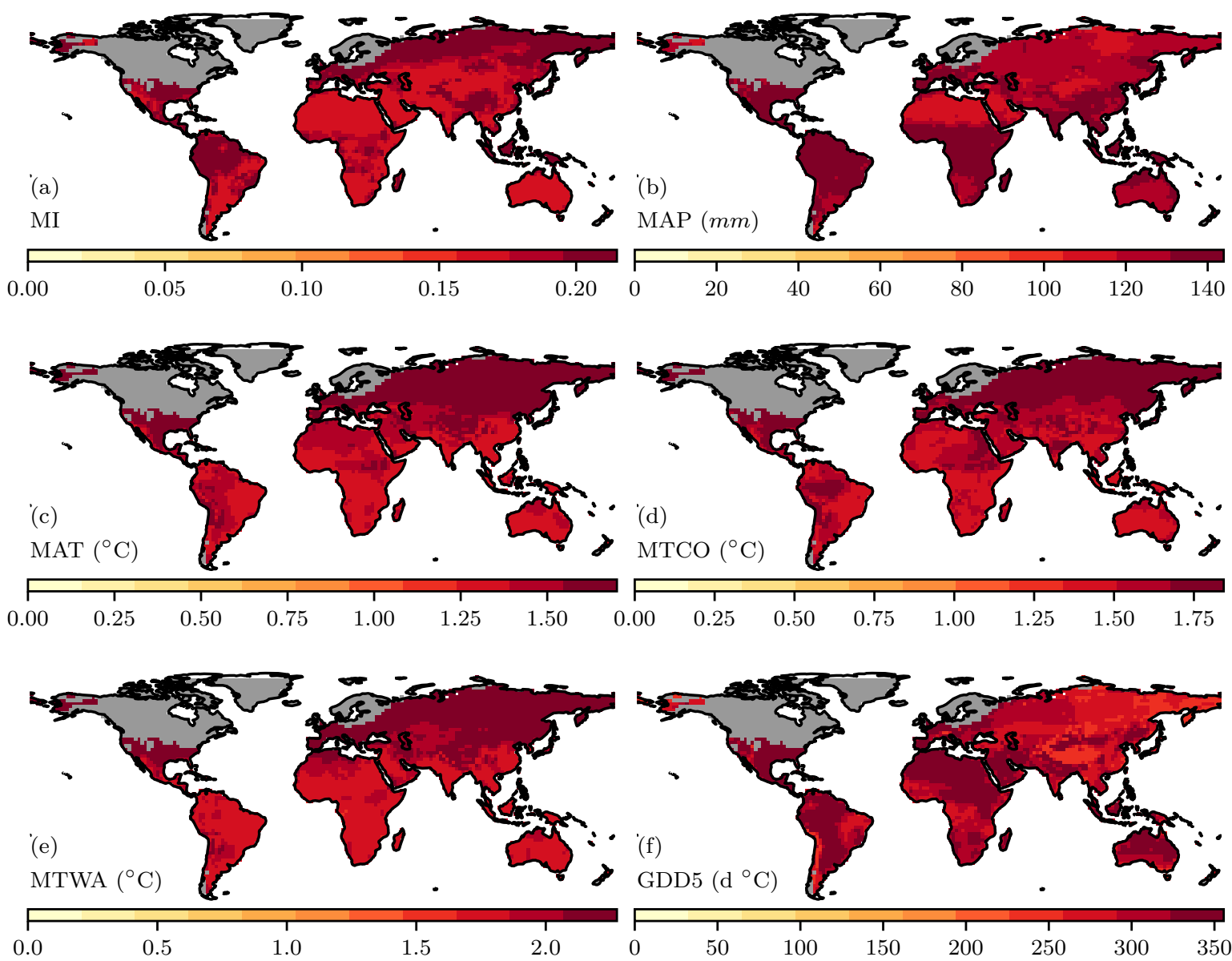
34 SI Figure 3: Site-based reconstructions of climatic variables at the Last Glacial Maximum. The plots 35 show reconstructions of (a) moisture index (MI), (b) mean annual precipitation (MAP), (c) mean 36 annual temperature (MAT), (d) mean temperature of the coldest month (MTCO), (e) mean 37 temperature of the warmest month (MTWA), and (f) growing degree days above a baseline of $5^{\circ} \mathrm{C}$ 38 (GDD5). The original reconstructions are from Bartlein et al. (2011) and Prentice et al. (2017).

39
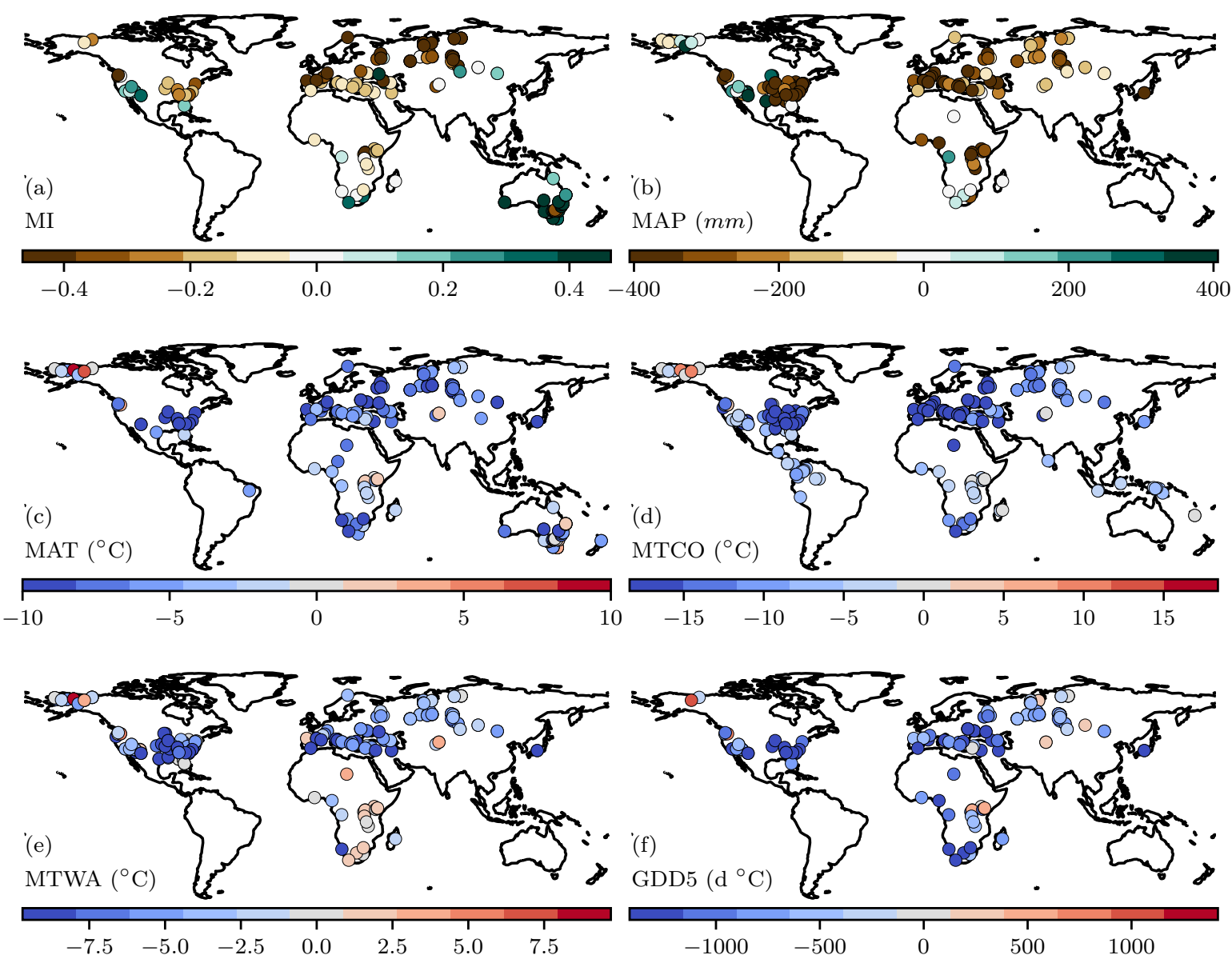